\title{
THE ROLE OF EXPERT EVIDENCE IN THE DEFENCE OF PROVOCATION AND EMOTIONAL STRESS IN SOUTH AFRICA
}

\author{
Sandhya Maharaj \\ LLB LLM PhD \\ Postdoctoral Researcher, University of KwaZulu- \\ Natal
}

\section{SUMMARY}

The provocation defence has emerged as one of the most contentious defences in modern times and has remained that way for many years in jurisdictions such as South Africa, England and Canada. In South Africa, the courts have struggled in deciding what role, if any, provocation should occupy in criminal law. This dynamic approach arises from the psychological or principle-based approach to crimina liability. Provocation and emotional stress are powerful emotions. In South Africa, the criminal law recognises that these emotions may impact criminal liability by causing a temporary loss of criminal capacity. The three notorious acquittals in $S v$ Nursingh, $S$ $\checkmark$ Arnold and $S v$ Moses created controversy for the defence. In an attempt to bring clarity to this area of the law and to calm public outrage the court in Eadie effected fundamental changes in the form of a policy brake on the principles underpinning the defence. Unfortunately, this brought more confusion to the defence. However, it is submitted that the uncertain role of expert evidence in relation to this defence has arguably been a source of the problems encountered in the application of this defence. A measure of uncertainty exists regarding what, if any, the role of expert evidence plays in cases involving non-pathological incapacity due to provocation Reform and development is needed to formulate a new approach not only to provide clarity but also to ensure improved functioning of the defence. The rules governing expert opinion evidence in respect of the defence of non-pathological incapacity are in need of review and legislative intervention.

INTRODUCTION

Provocation and emotional stress are powerful emotions. In South Africa, the criminal law recognises that these emotions may impact criminal liability by causing a temporary loss of criminal capacity. This is the nature of the defence of non-pathological incapacity due to provocation and emotional stress. This defence is one of the most debated defences in South African criminal law; on a basic level, the very notion of permitting provocation to function as a defence excluding criminal liability is controversial. ${ }^{1}$

Hoctor "A Peregrination Through the Law of Provocation" in Joubert (ed) Essays in Honour of CR Snyman (2008) 110; Snyman Criminal Law 6ed (2014) 159 notes that the term "non- 
The principle-based approach to provocation and emotional stress, though logical and in line with the interests of justice and fairness, has been under scrutiny since its development. ${ }^{2}$ Commentators argue that the defence is inherently problematic and should, primarily on grounds of policy, be limited to prevent the "hothead" from being acquitted. ${ }^{3}$

Critics propose that South African law should align itself with AngloAmerican systems, which take a more stringent stance towards provocation. ${ }^{4}$ The controversy surrounding a defence based on provocation stems from the view that an individual should not be able to use a loss of temper to justify or excuse the killing of another human being.

\section{A CONTENTIOUS DEFENCE IN MODERN TIMES}

The provocation defence has emerged as one of the most contentious defences in modern times and has remained that way for many years in jurisdictions such as South Africa, England and Canada. The dilemma in England and Canada centres on ensuring there is room for a concession to human infirmity on the one hand, while simultaneously ensuring that the law does not condone unacceptable standards of behaviour. ${ }^{5}$

An important basic principle in most modern legal systems is that acts of vengeance (argued to be the main motivation behind retaliation to provocation) should not only be discouraged, but punished. ${ }^{6}$ It is due to these considerations of policy that the provocation defence in England and Canada exists only as a partial defence to murder. ${ }^{7}$

The general approach in jurisdictions such as England and Canada is that a provoked act cannot completely excuse the agent from criminal liability, but only partially, as fundamentally, individuals are expected to exercise control over their emotions and their actions. Achieving this balance between recognising human frailty and enforcing a standard of acceptable behaviour

pathological incapacity" has been given by the courts to describe circumstances where mental illness or immature age is not pleaded. This term was first formulated in $S v$ Laubscher 1988 (1) SA 163 (A) in order to differentiate the defence from mental illness as contained in section 78(1) of the Criminal Procedure Act.

2 See discussion in Burchell "Non-Pathological Incapacity: Evaluation of Psychiatric Testimony" 19958 SACJ 3741.

3 See $R$ v Krull 1959 (3) SA 392 (A) 396; see discussion by Dugard "Provocation: No More Rides on the Sea Point Bus - Recent Cases" 196683 SALJ 262.

4 Snyman "The Tension Between Legal Theory and Policy Considerations in the General Principles of Criminal Law" 2003 Acta Juridica 1 12-13.

5 See discussion in Wells Provocation: The Case for Abolition - Rethinking English Homicide (2000) 86 and Dick "A Tale of Two Cultures: Intimate Femicide, Cultural Defences and the Law of Provocation” 201123 Canadian Journal of Women and the Law 519522.

6 Mitchell "Years of Provocation, Followed by a Loss of Control" in Zedner and Roberts (eds) Principles and Values in Criminal Law and Criminal Justice: Essays in Honour of Andrew Ashworth (2012) 113 113; see further Horder "Reshaping the Subjective Element in the Provocation Defence" 200525 Oxford Journal of Legal Studies 123 123-124.

7 Ashworth "The Doctrine of Provocation" 1976 35(2) Cambridge LJ 292 317; see discussion in Allen "Provocation's Reasonable Man: A Plea for Self-Control" 200064 Journal of Criminal Law 216. 
in society is where the controversy in jurisdictions such as England and Canada emerges. ${ }^{8}$

\section{A DYNAMIC SOUTH AFRICAN APPROACH}

This approach is in stark contrast to the approach in South Africa, where the law during the past quarter of a century has gone so far as to allow provocation and emotional stress to operate as a complete defence. This dynamic approach arises from the psychological or principle-based approach to criminal liability, which is based on the legal principle that unless an individual possesses the capacity or the fair opportunity to regulate his or her behaviour in accordance with the requirements of the law, the consequences of the behaviour should not apply. ${ }^{9}$

The Laubscher ${ }^{10}$ case provided a theoretical framework for the defence and stated that, in terms of legal principle, non-pathological incapacity could lead to an acquittal. The defence of non-pathological incapacity thus gained an autonomous existence independent of the defence of pathological incapacity. The court emphasised that in order for an accused to be criminally accountable, the accused's mental faculties must be such that he is legally to blame for his conduct. ${ }^{11}$

The law distinguishes between conduct that is uncontrolled and that which is uncontrollable; it is uncontrolled actions that attract criminal liability as the conduct is blameworthy. ${ }^{12}$ This attitude towards provocation and emotional stress in South African law is far-reaching as it offers the accused a complete acquittal if evidence is adduced on behalf of the accused that is sufficient and compelling to create a reasonable doubt regarding the presence of criminal capacity due to factors such as "emotional stress" or "emotional breakdown".

The theoretical framework underpinning the notion of loss of self-control, which derives much of its content from the Rumpff Commission Report ${ }^{14}$ and the case of Laubscher,${ }^{15}$ provides guidance on the application of the test for capacity.

\section{THE DIRE EFFECT OF PROVOCATION AND EMOTIONAL STRESS ON CRIMINAL CAPACITY}

In terms of this defence, provocation or severe emotional stress has been recognised to deplete an individual's power of self-control thereby causing a

\footnotetext{
Ashworth 1976 Cambridge LJ 317.

Hoctor in Joubert Essays in Honour of CR Snyman 111 and 131.

$S v$ Laubscher supra.

$S v$ Laubscher supra 166D-167A.

Louw "S v Eadie: Road Rage, Incapacity and Legal Confusion" 200114 SACJ 206214.

Snyman Criminal Law 159-160.

The Report of the Commission of Inquiry into the Responsibility of Mentally Deranged Persons and Related Matters RP 69/1967 par 9.33.

15 S v Laubscher supra.
} 
disintegration of criminal capacity. ${ }^{16} \mathrm{~A}$ loss of criminal capacity means that an individual loses the ability to appreciate the wrongfulness of his or her conduct or to act in accordance with such appreciation.

The terms "emotional stress" and "provocation" are used synonymously. However, "emotional stress" indicates a build-up of stress over a period, whereas "provocation" suggests a once-off incident that sparks the agent into action. Nonetheless, the factors relating to emotional stress are usually inextricably tied to provocation. ${ }^{18}$

\section{APPROACH WITH CAUTION}

This defence is not restricted to incapacity arising out of provocation. The defence encompasses situations where an agent has been provoked to commit an action by emotions such as jealousy, mercy, ${ }^{19}$ anger ${ }^{20}$ or fear. ${ }^{21}$ The critical element is that in order to escape criminal liability, the provoked person must have suffered a total collapse of criminal capacity. ${ }^{22}$ However, it must be noted that a scenario where provocation in fact causes loss of criminal capacity is rare. ${ }^{23}$ The courts are aware of the dangers of this defence and will approach the defence with great caution. ${ }^{24}$

The general approach in many legal systems is that a provoked act cannot totally excuse the agent from criminal liability as, fundamentally, individuals are expected to exercise control over their emotions and their actions. Allowing provocation as a defence poses many legal and moral dilemmas.

\section{A SERIES OF UNFORTUNATE EVENTS}

In South Africa, the courts have also struggled in deciding what role, if any, provocation should occupy in criminal law. The three notorious cases that have brought controversy to the provocation defence are $S v$ Nursingh, ${ }^{25} S v$ Arnold ${ }^{26}$ and $S v$ Moses.

16 Carstens and Le Roux "The Defence of Non-Pathological Incapacity with Reference to the Battered Wife Who Kills Her Husband" 200013 SACJ 180182.

17 Carstens and Le Roux 2000 SACJ 182.

18 Louw "S v Eadie: The End of the Road for the Defence of Provocation?" 200416 SALJ 200 201; Hoctor in Joubert Essays in Honour of CR Snyman 111.

19 See S v Hartmann 1975 (3) SA 532 (C). In this case, the accused killed his father, who was suffering from terminal cancer.

20 In S v Mokonto 1971 (2) SA 319 (A) 324F-G, Holmes JA stated that "[p]rovocation and anger are different concepts, just as cause and effect are. But in criminal law, the term provocation seems to be used as including both concepts, throwing light on an accused's conduct".

21 See S v Campher 1987 (1) SA 940 (A) and S v Wiid 1990 (1) SA 561 (A).

22 Snyman Criminal Law 160.

23 Snyman Criminal Law 165.

24 Hoctor in Joubert Essays in Honour of CR Snyman 130; Carstens and Le Roux 2000 SACJ 182; see S v Kensley 1995 (1) SACR 646 (A)

1995 (2) SACR 331 (D).

1985 (3) SA 256 (C).

$27 \quad 1996$ (1) SACR $701(\mathrm{C})$. 
These cases fueled the debate on the acceptability of a defence based on provocation and emotional stress, and highlighted the risk of facile acquittals. However, the acquittals in these cases unearthed problems relating to application of principle rather than the principle itself. It is submitted that in each case, a series of goal-directed acts on the part of the accused indicated the presence of conative capacity, volitional control and insight on the part of the accused therefore indicating that capacity was not lacking. ${ }^{28}$

It is submitted that these cases were wrongly decided and that this brought the defence of non-pathological incapacity due to provocation and emotional stress into disrepute. However, it is apparent that the unjust acquittals in these cases were a direct result of a failure by the courts properly to apply the fundamentals of the defence to the facts.

In an attempt to bring clarity to this area of the law and to quell the public outrage arising from the acquittals in Arnold, ${ }^{29}$ Nursingh, ${ }^{30}$ and Moses, ${ }^{31}$ the court in Eadie ${ }^{32}$ effected fundamental changes in the form of a policy brake on the principles underpinning the defence of non-pathological incapacity, which, in a drastic turn of events, has led to uncertainty regarding whether the defence of non-pathological incapacity still exists. Hence, the leading case of Eadie has unfortunately brought more confusion to the defence rather than repairing the damage done to the defence.

\section{THE UNCERTAIN ROLE OF EXPERT EVIDENCE}

While the acquittals in Nursingh, ${ }^{33}$ Arnold $^{34}$ and Moses $^{35}$ were extremely controversial, the three cases reveal a troubling aspect of the defence, a weakness that centres around expert evidence and its uncertain and unregulated relation to the defence.

In South African law, expert evidence is not a prerequisite and is not considered indispensable; a plea of non-pathological incapacity may therefore be raised without the leading of expert evidence. ${ }^{36}$ There is a presumption in law that an accused person possesses the required criminal capacity in cases where there is no evidence suggesting mental illness. This presumption applies equally to cases where the accused was intoxicated or in an enraged state. ${ }^{37}$

The courts approach a defence based on non-pathological incapacity with caution and circumspection, and therefore the success of a case will often

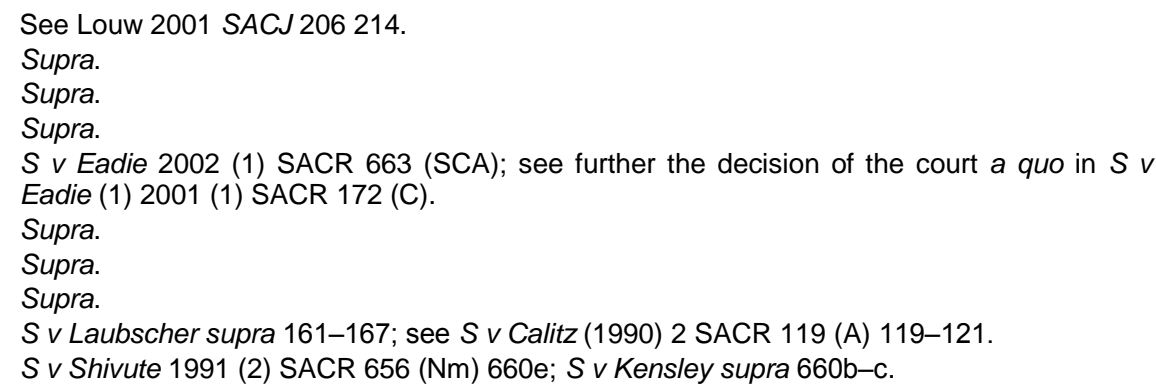


depend on expert evidence. ${ }^{38}$ The court will view with circumspection the evidence supporting a defence of non-pathological incapacity due to provocation and emotional stress, and such a defence will be more carefully scrutinised. This applies especially to cases where the only evidence is the ipse dixit of the accused since the trustworthiness of this evidence depends on the authenticity of the factual foundation. ${ }^{39}$

It can be deduced that expert evidence in support of this defence is considered important. ${ }^{40}$ However, it is not mandatory; expert testimony is not essential for succeeding, but is only advisable as it may prove a useful aid to a court by shedding light on an accused's mental abilities. ${ }^{4}$

A measure of uncertainty exists regarding what, if any, the role of expert evidence plays in cases involving non-pathological incapacity due to provocation. ${ }^{42}$ Cases such as Campher ${ }^{43}$ and Calitz ${ }^{44}$ indicate that expert evidence is not regarded as crucial for the defence to succeed. ${ }^{45}$ Van Oosten notes in contrast that certain dicta indicate that courts explicitly require expert evidence in the form of psychiatric or psychological evidence for the defence of provocation to succeed. ${ }^{46}$ Based on the Campher ${ }^{47}$ and Calitz $^{48}$ judgments, it is however arguable that it is more advantageous raising the defence of non-pathological, rather than pathological, incapacity since, in the latter defence, success hinges on psychiatric evidence and the accused raising pathological incapacity is under onus of proving the lack of capacity on a balance of probabilities.

Although the State bears the onus of proving the presence of criminal capacity beyond a reasonable doubt, the accused is under a duty to lay a factual foundation for the defence, which must be sufficient to create a reasonable doubt on the point. ${ }^{50}$ It is also unclear if expert evidence is required to lay the factual foundation for the defence.

38 Carstens and Le Roux 2000 SACJ 181-182.

39 Hoctor in Joubert Essays in Honour of CR Snyman 130 citing $S v$ Kensley supra 658g-h and S $v$ Gesualdo 1997 (2) SACR 68 (W) 74g-h, where the court stated that it "would be unlikely to find that such a state [incapacity] may have existed only by virtue of the accused's ipsissima verba". See further Carstens and Le Roux 2000 SACJ 182

40 Carstens and Le Roux 2000 SACJ 182

41 See $S v$ Wiid supra 564c-f and $S v$ Arnold supra.

42 Van Oosten "Non-Pathological Criminal Incapacity Versus Pathological Criminal Incapacity" 19936 SALJ 127141.

$43 \quad S$ v Campher supra.

$44 \quad S v$ Calitz supra.

45 See further $S$ v Eadie (1) 2001 (1) SACR 172 (C) 180e-g; S v Kok 1998 (2) SACR 532 (N) 545j-546a; $S$ v Laubscher supra 172E-F and $S v$ Volkman 2005 (2) SACR 402 (C) par 11 and 13.

46 Van Oosten 1993 SALJ 127141 citing Boshoff AJA in S v Campher supra 966J-967C; S v Wiid supra $564 \mathrm{c}-\mathrm{f}$.

$47 \quad S v$ Campher supra.

$48 \quad S v$ Calitz supra.

9 Van Oosten 1993 SALJ 127146.

50 Hoctor in Joubert Essays in Honour of CR Snyman 129 citing S v Eadie 2002 (1) SACR 663 (SCA) par 2; S v Kalogoropoulos 1993 (1) SACR 12 (A) 21i-j; S v Di Blasi 1996 (2) SACR 1 (A). 


\section{THE ROLE OF EXPERT EVIDENCE IN NURSINGH ${ }^{1}$}

There is much confusion surrounding the issue of expert evidence in respect of the defence under discussion. It is submitted that the fact that the leading of expert evidence is not mandatory has had a tremendous impact on the application of the defence. The uncertain role of expert evidence in relation to this defence has arguably been a source of the problems encountered in the application of this defence, and may have contributed to the outcome of the notorious case of Nursingh.

Expert witnesses on behalf of the defence were of the opinion that the accused suffered an altered state of consciousness at the time of the shooting. This altered state of consciousness allegedly deprived the accused of an awareness of normality. He had a mental state where his intellect and emotions were separated. ${ }^{52}$

The psychiatrist stated that despite the accused's goal-directed behaviour, "he would be using no more intellect than a dog biting in a moment of response to provocation". The court accepted that the accused's series of goal-directed acts constituted only one act in each case. ${ }^{53}$

According to the psychiatrist, this syndrome is well documented in psychiatric research and literature. This state was brought about by provocation by his mother and, together with his personality make-up and years of abuse, triggered a state of altered consciousness.

The psychologist on behalf of the defence stated further that the accused suffered an:

"[a]cute catathemic crisis resulting in an overwhelming of the normal psychic equilibrium by an all-consuming rage, resulting in the disruption and the displacement of logical thinking manifesting itself in an explosion of aggression that frequently leads to homicide".

Expert witnesses stated that in certain relationships conflict leads to "unbearable tension". The built-up tension is released in a violent way when triggered by a certain event. ${ }^{56}$

A significant feature of Nursingh is that the prosecution did not lead expert testimony to rebut the expert evidence led by the defence. The difficulties arising from this is that the court hears one side only, and the testimony of the expert witness remains untested. With only the defence version being presented and supported by expert testimony, the State's case is essentially doomed to fail. The accused was subsequently acquitted on all three charges of murder.

\footnotetext{
Supra.

$S \vee$ Nursingh supra 333d-e.

Ibid.

$S$ v Nursingh supra 333c-d.

$S v$ Nursingh supra $333 \mathrm{e}-\mathrm{h}$.

$S v$ Nursingh supra 3331.
} 
Squires $\mathrm{J}$ stated that the accused succeeded in laying a factual foundation strong enough to cast a reasonable doubt on the presence of criminal capacity. ${ }^{57}$ Burchell states that it is difficult to find fault with the judgment of Squires $\mathrm{J}$ in Nursingh since evidence was heard and the learned judge formed the opinion that there was a reasonable possibility that the accused was being truthful, and that the expert psychological and psychiatric testimony led by the defence, although uncontested, was compelling. Since the test for criminal capacity is subjective, when doubt emerges as to the presence of capacity, the accused must be given the benefit of that doubt and receive an acquittal. ${ }^{58}$

This case demonstrates at first hand how the uncertainty regarding the necessity of calling expert evidence may lead to a questionable acquittal. In particular, the Nursingh case highlights evidentiary problems specifically related to how expert evidence is governed in cases involving nonpathological incapacity due to provocation and emotional stress, and demonstrates the need for judges to demand expert evidence to achieve a balanced view and properly assess the validity of an accused's version of the defence.

In the case of Arnold $^{59}$ the State also did not lead expert psychiatric evidence in support of its case; nor did it challenge the opinion evidence led by the defence witness. An imbalance of expert evidence may clearly deprive a court of a balanced view and result in inconsistent case law. Thus, in order for a defence to function properly, this problem must be addressed.

Burchell recommends two practical solutions. First, a judge should require the prosecution to lead expert psychologist and psychiatrist testimony. This would test the evidence led by the defence against evidence led by the State. ${ }^{60}$ Such a procedure would be similar to that provided for in cases of insanity under section 79 of the Criminal Procedure Act, ${ }^{61}$ which requires evidence from a court-appointed psychiatrist as well as a psychiatrist appointed by the defence.

According to Burchell, this would ensure that the court obtains a balanced, well-informed view and would work to prevent facile acquittals and ensure consistent outcomes of cases. The defence of non-pathological incapacity is lacking in this respect; consultation and review of this area is required with the view to formulating a procedure consistent with the provisions of the Criminal Procedure Act.

A provision to this effect, in the context of the defence of non-pathological incapacity, would ensure that the law in this area is consistent and would also act as a safeguard to prevent facile acquittals. The ultimate aim of the expert testimony would be to obtain a "balanced view", which is better than a one-sided perspective. ${ }^{63}$ Stevens argues that one of the problems facing the

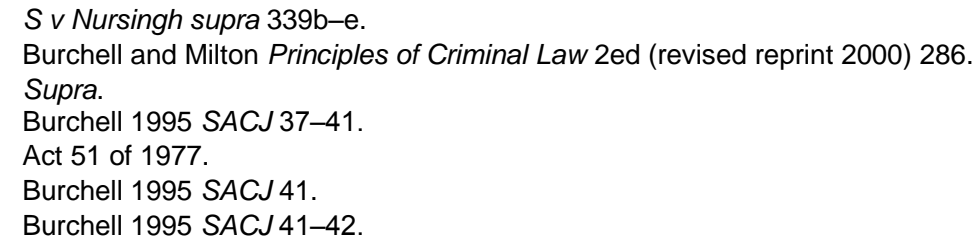


defence of non-pathological incapacity is that a legal framework governing the assessment of evidence upon which the defence relies does not exist; in contrast, the defence of pathological incapacity is governed by the Criminal Procedure Act. ${ }^{64}$

Thus the issue that arises is whether expert evidence must be made mandatory, and furthermore, what type of framework should be developed to regulate expert evidence in the context of a defence that caters specifically for those that have lost capacity by non-pathological causes.

However, applying the same regulations to the defence of nonpathological incapacity may result in the fundamental distinction between the two types of defence fading away. The effect of this may be adverse to victims of abuse (such as the "battered woman") who run the risk of being categorised as insane or deranged when in fact they may not possess a mental disorder or defect. Merging the two defences and applying the same rules may defeat the purpose of having a defence based on non-pathological incapacity, which addresses the needs of the sane. The defences of sane automatism and non-pathological incapacity are fundamentally different; any framework formulated to cater for the latter must do justice to the unique nature of the defence of non-pathological incapacity, and ensure that expert evidence is an aid but is not regarded as the defining factor.

\section{THE BATTERED WOMAN}

In South Africa, the courts have used a range of terminology to define the symptoms of battered woman syndrome, including terms such as "impulsive mania" in the case of Campher ${ }^{65}$ and "emotional flooding of the mind" in Smith. ${ }^{66}$ The cases of Wiid $^{67}$ and Smith $^{68}$ both recognise that emotional stress can result in a complete lack of criminal capacity.

The battered woman syndrome was formulated by Dr. Lenore Walker, an eminent American psychologist. ${ }^{69}$ Dr Walker identified the principal elements of battered woman syndrome, describing a "battered woman" as a woman who is the object of repeated forceful physical and psychological conduct by a man, with the intention of coercing her to act in a way where she disregards her own well-being. One of the main attributes of battered woman syndrome is that the abused woman must have been subjected to two cycles of battering. ${ }^{70}$ The theory of "learned helplessness" forms the basis of this theory and can be described as the lack of reaction when exposed to a threat.

64 Act 51 of 1977; Stevens The Role of Expert Evidence in Support of the Defence of Criminal Incapacity (unpublished LLD, University of Pretoria) 2011826.

65 Supra.

66 Carstens and Le Roux 2000 SACJ 188 discussing S v Smith 1990 (2) SACR 130 (A).

67 Supra.

68 Supra

69 See Walker The Battered Woman (1979). See further Krause Defences Available to Battered Women who Kill their Abusers: A Comparative Analysis (unpublished PhD thesis, University of KwaZulu-Natal) 200973.

70 Walker The Battered Woman 16.

71 lbid. 
Battered woman syndrome as formulated by Walker is classified as a subcategory of the generic Post-Traumatic Stress Disorder (PTSD), which is an anxiety disorder, and is included within the Diagnostic and Statistical Manual of Mental Disorders. ${ }^{72}$ The main symptoms suffered by these individuals include high arousal symptoms, an increased sense of danger and cognitive disturbances as well as depression or repression. ${ }^{73}$

The issue of emotional stress serving as a complete defence emerged in the case of Wiid, ${ }^{74}$ where the appellant had been convicted of murder in the court a quo for the killing of her husband. The deceased abused the appellant numerous times during their marriage. On the day of the killing, the appellant was assaulted severely. There were some indications that the appellant suffered a concussion as a result of the assault. After the assault, the appellant shot the deceased several times, killing him. The appellant was convicted of murder with extenuating circumstances and sentenced to five years' imprisonment, which sentence was suspended in totality.

The appeal court found that a reasonable doubt existed as to the voluntariness of the appellant's actions. The court could not reconcile the fact that the appellant loved the deceased with the possibility that she had consciously fired seven shots at him. The court accepted the possibility that the appellant may not have been fully conscious when the shots were fired. Therefore, the court found that the appellant lost self-control. The court was thus of the view that a reasonable doubt existed as to whether the appellant possessed criminal capacity at the time of the killing and that therefore the accused should be given the benefit of such doubt. Thus, the appeal succeeded. ${ }^{75}$ The court in Wiid recognised a general test for the defence of criminal incapacity.

In terms of the battered woman theory, the mind of the battered woman is adversely affected due to the effect of the series of beatings. In terms of this psychosocial learning theory, ${ }^{76}$ the battered woman experiences psychological changes because of trauma that reduces her motivation to react. ${ }^{77}$ This is due to the changes in her cognitive abilities, which become impaired. Her reaction to violence perpetrated against her does not depend on the severity of the last beating. The mind of the battered woman is fixated on the severity of the threat that the abuser poses to her life. Hence, the reaction of the battered woman cannot be considered an "over-reaction" at all. $^{78}$

72 American Psychiatric Association Diagnostic and Statistical Manual of Mental Disorders 5ed (2013) 271.

73 Walker The Battered Woman Syndrome (1984) 327-330.

74 Supra.

$75 \quad S \vee$ Wiid supra; see discussion by Ludsin "Notes and Comment: Ferreira $v$ The State: A Victory for Women Who Kill Their Abusers in Non-Confrontational Situations" 200420 South African Journal on Human Rights 642 175-176.

76 Walker The Battered Woman Syndrome 45-47.

77 Walker The Battered Woman Syndrome 49-50.

78 Edwards "Anger and Fear as Justifiable Preludes for Loss of Self-Control" 201074 Journal of Criminal Law 223233. 


\section{THE IMPORTANCE OF SYNDROME EVIDENCE}

Evidence in support of battered woman syndrome is referred to as syndrome evidence and usually consists of forensic psychiatric and psychological evidence that is intended to explain the behaviour of the accused or the provoker. Syndrome evidence may explain the impact of long-term violence on an individual. Syndrome evidence is therefore important in cases involving cumulative provocation. ${ }^{79}$

The uncertainties and debate regarding admissibility of expert testimony in cases involving the provocation defence are not limited to South Africa but extend to England and Canada where admissibility of expert evidence has garnered some attention. ${ }^{80}$ In England and Canada, the general position is that expert evidence is inadmissible in cases involving provocation; however, in England, this approach has been the subject of criticism as it is contended that certain behaviours or mental states cannot be understood without the assistance of a medical practitioner who specialises in the field of psychiatry or psychology. ${ }^{81}$

Furthermore, it has been contended that the scope of admissible evidence should be widened to include abnormal and unusual states of mind that cannot be categorised as mental illness and may not be understood by a layperson even with common sense. ${ }^{82}$ It is thus argued that expert testimony can be very useful in such cases as it may aid in understanding the mindset of the accused at the time of commission of the offence. ${ }^{83}$ This is especially important in cases involving battered women.

The courts have generally struggled with identifying criteria for admitting expert evidence. This problem is present in jurisdictions such as England, Australia, New Zealand and Canada. The value of expert evidence has been acknowledged by English courts and over many centuries, experts have provided a prominent role as witnesses on medical, scientific and literary matters. ${ }^{84}$ All experts are bound by an elevated duty to ensure that a court is not misled; this duty applies regardless of the ramifications to the party that they have been called for. ${ }^{85}$

In Canada $^{86}$ and Australia, ${ }^{87}$ evidence relating to battered woman syndrome has been admitted in a number of cases. Syndrome evidence has been regarded as important as it may shed light on the emotional make-up

79 Robertson "Battered Woman Syndrome: Expert Evidence in Action" 1998 9(2) Otago LR 277282.

80 Ward "Usurping the Role of the Jury? Expert Evidence and Witness Credibility in English Criminal Trial" 200913 International Journal of Evidence and Proof 83.

81 Coleman and Mackay "Legal Issues Surrounding the Admissibility of Expert Psychological and Psychiatric Testimony" 1993 Issues in Criminological and Legal Psychology 20 46, 49.

82 Mackay and Coleman "Equivocal Rulings on Expert Psychological and Psychiatric Evidence: Turning a Muddle into a Nonsense" 1996 Criminal LR 8895.

83 Mackay and Colman 1996 Criminal LR 95.

84 Coleman and Mackay 1993 Issues in Criminological and Legal Psychology 46.

85 Law Commission Expert Evidence in Criminal Proceedings in England and Wales (2011) No.325 par 1.22 .

$86 \quad R v$ Lavallee (1990) 1 S.C.R. 852.

$87 \quad R v$ Kontinnen and Runjajic (1991) 53 ACrimR 362. 
of an accused at the time of the commission of the killing and factors that make her more prone to provocation. ${ }^{88}$

The United States was the first to allow expert evidence in cases involving battered woman syndrome. ${ }^{89}$ Jurisdictions such as Canada, Australia and New Zealand followed the lead of the United States and began admitting evidence relating to battered woman syndrome. ${ }^{90}$ The admissibility of expert evidence in cases involving battered woman syndrome has been the source of debate in Canada, especially in light of the criticisms involving gender discrimination towards women. Expert evidence may be led to show that the emotional make-up of the accused made her more prone to provocation. ${ }^{91}$

The general approach in Canada is that expert evidence must satisfy a two-fold precondition test in order to be admitted. First, the expert opinion must be of value to the ordinary person; secondly, the expert must be qualified to give his or her opinion through experience, qualification or in practice. $^{92}$ Expert evidence will only assist the accused in terms of satisfying the subjective test - that is, in the assessment of the suddenness of retaliation and if loss of self-control actually occurred.

In the landmark case of Lavallee, ${ }^{93}$ which involved the battered woman syndrome in the context of self-defence, the Supreme Court of Canada allowed the admission of the expert evidence. Although this case did not involve the pleading of the provocation defence, it is relevant and important in respect of the court's treatment of expert evidence in relation to battered woman syndrome, which is used as the basis for the provocation defence in jurisdictions such as England and South Africa.

The court emphasised that expert evidence was necessary in order to shed light on the mental state of the accused and explain battered woman syndrome to the jury. The court stated that this was an aspect of human behaviour that was not common knowledge to the jury and therefore required assistance from an expert. ${ }^{94}$

Carstens and Le Roux have (it is submitted) correctly argued that in light of the realities of violence against women and the killings arising out of battered women syndrome, the expert evidence of mental health practitioners such as psychologists and psychiatrists is of paramount importance in the defence of such accused. ${ }^{95}$

Apart from the trial process, there is another area that deserves some attention - that is, whether there is a need for the psychiatric evaluation of the accused with the precise extent and nature of evaluation also to be

\footnotetext{
Mackay and Coleman 1996 Criminal LR 95.

State $v$ Kelly 97 N.J 178; 478 A.2d 364 (1984).

Quigley "Deciphering the Defence of Provocation" 198938 University of New Brunswick LJ 1129.

91 Nelson "Enraged or Engaged: The Implications of Racial Context to the Canadian Provocation Defence" 2001-2002 University of Richmond LR 10071056.

92 Stuesser "The 'Defence' of 'Battered Woman Syndrome' in Canada" 199019 Manitoba LJ 195 198-199.

93 Supra.

$94 \quad R$ v Lavallee supra 889-890.

95 Carstens and Le Roux 2000 SACJ 187.
} 
determined. This should ideally take place before the trial. This is especially important considering the nature of the defence, which involves emotional stress, emotional collapse, shock and fear as well as provocation. Even though these emotional disturbances are non-pathological in nature, the law should provide for an avenue wherein accused persons may be referred for short periods of psychiatric evaluation.

In the South African context, it has been argued that it is in the interests of justice that the victim of battering (the battered accused) receive evaluation by relevant mental health practitioners along with counselling to ensure that she is prepared for trial. This would ensure that the accused is emotionally capably of collecting evidence needed in her defence. One of the main hurdles in the way of an accused person such as a battered woman is that expert evidence is not compulsory. This is problematic to accused persons requiring expert evidence in laying a factual foundation for the defence. A lack of expert evidence can therefore be prejudicial to the accused. ${ }^{96}$ The evidence of psychologists, psychiatrists and social workers may be crucial to an accused's defence.

It has generally been accepted that a battered woman suffers from a form of post-traumatic stress disorder; therefore, regulating this area of the law in order to allow for referrals for psychiatric evaluation and counselling is likely to benefit an accused person. ${ }^{98} \mathrm{~A}$ court has a discretion whether to refer an accused for psychiatric evaluation as laid out in section 79 of the Criminal Procedure Act. ${ }^{99}$ However, the defence of non-pathological incapacity is inadequate in this respect; consultation and review of this area is required with a view to formulating a procedure that could form part of the provisions of the Criminal Procedure Act.

It is recommended that legislation be implemented to address the procedural shortcomings and uncertainty relating to the proffering of expert evidence in cases involving non-pathological incapacity due to provocation and emotional stress.

\section{EXPERT OPINION VS LEGAL PRINCIPLE}

In the case of Mahlinza, ${ }^{100}$ Rumpff JA emphasised that the concepts of "criminal liability" and "elements of a crime" are legal concepts, whereas the concepts of "mental illness" and "mental defect" are psychiatric ones. The evidence of medical experts is important but not conclusive. ${ }^{101}$ This point is especially significant in relation to the views of medical health practitioners on cases involving non-pathological incapacity and sane automatism, which are fundamentally different in terms of legal doctrine in South African law.

\footnotetext{
Stevens The Role of Expert Evidence in Support of the Defence of Criminal Incapacity 356.

Carstens and Le Roux 2000 SACJ 187.

98 See discussion above at heading 9.

99 Act 51 of 1977. Hoctor in Joubert Essays in Honour of CR Snyman 129; see $S$ v Volkman supra par 7-8.

100 S v Mahlinza 1967 (2) SA 408 (A).

101 S v Mahlinza supra 416B.
} 
Along with the influence of expert evidence comes another danger - that the sceptic will exert an unwelcome influence over the court, resulting in the favouring of medical science over legal principle. This is ultimately prejudicial to an accused who pleads this defence since it renders the defence pointless if the court itself does not consider the defence valid. Expert testimony in cases involving the defence of non-pathological incapacity due to provocation and emotional stress may potentially act as an obstacle preventing the defence from functioning.

Psychiatrists and other mental health care professionals are in most circumstances called to give evidence as expert witnesses. However, ironically, the medical fraternity doubts the very existence of the defence of non-pathological incapacity. ${ }^{103}$ This was the situation in the case of Kensley where the expert witness, a forensic psychiatrist, determined that the accused suffered from "no pathology recognised in psychiatry". ${ }^{104}$

One of the principles at the heart of the defence is the notion of "loss of self-control", which is a legal phenomenon and cannot be attributed to a pathological condition. ${ }^{105}$ In terms of the expert testimony, the notion of loss of self-control is not a clinical term but is a legal concept. ${ }^{106}$ It is precisely this lack of a mental defect that mental health practitioners find problematic. The medical fraternity do not in most circumstances draw a distinction between the defences of sane automatism, on the one hand, and loss of self-control emanating from the absence of conative functions, on the other. ${ }^{107}$

In most cases, the scepticism of mental health practitioners towards the defence of non-pathological incapacity is problematic to the accused since, in most cases, an expert may only be willing to concede the possibility of diminished responsibility and not a lack of criminal capacity. Furthermore, although the onus is on the State to prove that an accused possessed criminal capacity beyond a reasonable doubt, the accused is still under a duty to lay a factual foundation, and expert evidence will be needed in order to meet this requirement. ${ }^{108}$ It is doubtful that a factual foundation based on a report by a sceptic of the defence will be sufficient.

\section{EXPERT EVIDENCE: A DOUBLE-EDGED SWORD}

The argument over the importance and necessity of expert evidence is only one aspect of this investigation. There is another important consideration that deserves discussion - that is, the influence of expert testimony (steeped as it is in medical science) on the law and its principles.

There is a delicate balance between ensuring that input from medical experts is obtained while at the same time ensuring that the expert opinion

102 See discussion below at heading 12.

103 Carstens and Le Roux 2000 SACJ 182.

104 S v Kensley supra 652i-653h.

105 Stevens The Role of Expert Evidence in Support of the Defence of Criminal Incapacity 82-83.

106 Le Roux and Stevens "Pathological Criminal Incapacity and the Conceptual Interface between Law and Medicine" 20121 SACJ 4452.

107 Kaliski Psycholegal Assessment in South Africa (2007) 52.

108 Carstens and Le Roux 2000 SACJ 183. 
does not dictate what the final verdict should be. Principles governing the admissibility of expert evidence were summarised in the case of Engelbrecht:

"Firstly, in the matter in respect of which the witness is called to give evidence should call for specialised skill and knowledge. Secondly, the witness must be a person with experience or skill to tender her or him an expert in particular subject. Thirdly, the guidance offered by the expert should be sufficiently relevant to the matter in issue to be determined by the court. Fourth, the expertise of any witness should not be elevated to such heights that the court's own capabilities and responsibilities are abrogated. Fifth, the opinion offered to the court must be proved by admissible evidence, either facts within the personal knowledge of expert or on the basis of facts proven by others. Sixth, the opinion of such witnesses must not usurp the function of the court."

There is a real danger of over-reliance on such opinion to the extent that medical science is favoured over legal principle. It is potentially problematic if a court places reliance on the views of experts and allows expert testimony to dictate the outcome of a case. In assessing the case law involving the non-pathological incapacity due to provocation and emotional stress, it is apparent that there is a tendency of experts such as psychologists and psychiatrists to conflate the defence of sane automatism and nonpathological incapacity.

\section{THE ROLE OF EXPERT EVIDENCE IN $A R N O L D^{111}$}

In case of Arnold, the defence of non-pathological incapacity based on provocation and emotional stress was successful. However, this case generated debate over the decision to allow emotional stress or any other form of provocation to operate as a complete defence. The court acknowledged that emotional factors could contribute to a lack of capacity thereby leading to an acquittal as a result of provocation.

Snyman is a fierce critic of this case and argues that the court erred in acquitting the accused. In this case, the accused, a 41-year-old man, was charged with killing his wife, a 21-year-old woman. Defence counsel led psychiatric testimony to support the assertion that, at the time of the killing, the accused's mind overflowed with emotions and that as a result he may have lost the ability to control his actions or that he may have acted subconsciously when shooting his wife. ${ }^{112} \mathrm{Dr}$ Gittleson, a psychiatrist, appeared on behalf of the defence and gave expert testimony. It is interesting to note that the State did not call a psychiatrist and did not contest the expert evidence given by Dr Gittleson.

$109 S v$ Engelbrecht (2005) 2 SACR 41 (W) par 26.

110 Hoctor in Joubert Essays in Honour of CR Snyman 166.

111 Supra.

112 S v Arnold supra 263 C-E. See discussion in Snyman "Is There Such a Defence in our Law Criminal Law as 'Emotional Stress'?” 1985 SACJ 240.

113 S v Arnold supra 262F. 
The defence witness, Dr Gittleson, conducted a thorough investigation and testified that the accused's conscious mind was flooded by emotions, which interfered with his capacity to appreciate what was right and wrong. ${ }^{114}$ Owing to the severity of his emotional disturbance, the accused might have lost the capacity to exercise control over his actions. The court stated that there was reasonable doubt that the accused had acted consciously at the significant moment. ${ }^{115}$

Furthermore, $\mathrm{Dr}$ Gittleson stated that the accused had acted subconsciously at the crucial time owing to the emotional storm and therefore did not know what he was doing. However, the intensity of the storm was a question of degree and the expert witness could not say for certain whether the accused was conscious of what he was doing or not. ${ }^{11}$

The defence placed voluntariness of the accused's conduct and criminal capacity in issue. ${ }^{117}$ The accused was found not guilty as the court (per Burger J) accepted his version of events. The court stated that it could not be found that when the accused killed he was acting consciously and not subconsciously. ${ }^{118}$ However, if he was indeed acting consciously it had not been proven beyond a reasonable doubt that criminal capacity was present.

This case is an example of expert witnesses blurring the lines between the defences of non-pathological incapacity and sane automatism, which amounts to "fudging of doctrinal distinctions". ${ }^{119}$ This error proved problematic in this case as the court relied on the uncontested evidence by the defence and found that it could not find beyond a reasonable doubt that the accused acted consciously when killing the deceased.

Hoctor states that a "puzzling" feature of this judgment is that the court found it reasonably possible that the accused was acting in a state of sane automatism at the time of the shooting but nevertheless proceeded to hold that it was reasonably possible that the accused was lacking capacity at the time of the death of his wife. ${ }^{120}$ However, the court was mindful of the need to proceed with caution when accepting that the accused lacked capacity. The court was of the opinion that due to the "most unusual" of facts in the case, the accused may not have had control of his conduct. ${ }^{121}$

\section{THE UNFORTUNATE EFFECTS OF EADIE ${ }^{122}$}

Another unfortunate example of this phenomenon is the leading case of Eadie, which has redefined the principles governing the defence in South African law. The case related to "road rage", the exact ambit of which term is not clear but is understood to encompass volatile emotions such as

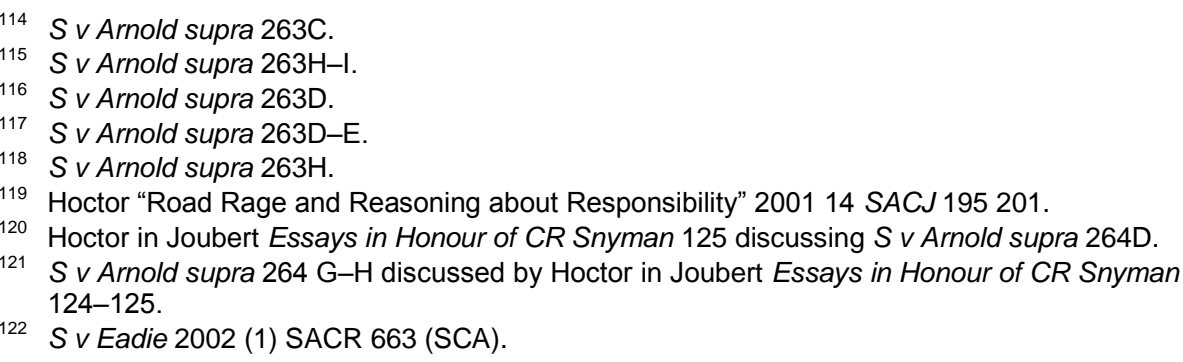


aggression, frustration and the feeling of authority and power whilst driving; the mixture of emotions creates a stressful condition leading to road rage. ${ }^{12}$

Arguably, the two most controversial aspects of the judgment relate first to the conflation of the defences of sane automatism and non-pathological incapacity, and secondly, to the apparent introduction of an objective test into the capacity inquiry. The ramifications of the conflation are tremendous and far-reaching since it essentially cancels the defence by denying its separate nature. ${ }^{124}$ Note that the judgment itself has had varied interpretations with some academics welcoming its pronouncements, ${ }^{125}$ while others have been strongly critical of certain aspects. ${ }^{126}$ The erosion of the defence is unwelcome and not in the interests of justice as it deprives individuals (such as the battered woman) of a defence. ${ }^{127}$

It is important to understand the basis for the court's reasoning and events that led up to the unwanted conflation. The court's analysis of the expert evidence played a central role in the way the case unfolded.

Stevens correctly argues (it is submitted) that the exact role and impact of the expert evidence in Eadie is difficult to assess. ${ }^{128}$ It is interesting to note that Navsa JA stated that the approach to the defence of Dr Kaliski (an expert witness for the State) was preferred. Dr Kaliski's view was that the defence has never been established and that there was no difference between the defence of sane automatism and non-pathological incapacity. ${ }^{129}$ However, ultimately Dr Kaliski was willing to concede the validity of the defence in the face of compelling facts. ${ }^{130}$

The court was clearly persuaded by $\mathrm{Dr}$ Kaliski's views and this undoubtedly contributed in part to the conflation of the defence of nonpathological incapacity and sane automatism. Dr Kaliski stated that in 90 percent of the cases that he has testified in, the defence raised was the same as the one raised by the accused. ${ }^{131}$

The court placed reliance on the testimony of Dr Kaliski along with this statement by Louw:

"Logic ... dictates that we cannot draw a distinction between automatism and lack of self-control. If the two were distinct, it would be possible to exercise

23 Hoctor 200114 SACJ 195196.

24 Hoctor in Joubert Essays in Honour of CR Snyman 134; Snyman 2003 Acta Juridica 117.

125 Snyman Criminal Law 164 welcomes the court's recognition of the need for an objective factor within the concept of culpability; Louw 200114 SACJ 206206 states: "Navsa JA's judgment is an extremely thorough one in which he systematically traces the development of the defence of non-pathological incapacity due to emotional stress and provocation."

126 Hoctor in Joubert Essays in Honour of CR Snyman 110 states: "[D]espite the wellestablished nature of the defence of non-pathological incapacity, the law has been thrown into flux by the decision of the Supreme Court of Appeal in $S v$ Eadie"; Snyman Criminal Law 161-163 is critical of the court's conflation of the distinct concepts of conative capacity and voluntariness.

127 Hoctor "Tracing the Origins of the Defence of Non-Pathological Incapacity in South African Criminal Law" 201117 Fundamina 7082.

128 Stevens The Role of Expert Evidence in Support of the Defence of Criminal Incapacity 280.

$129 S$ V Eadie (SCA) supra par 14.

$130 S v$ Eadie (SCA) supra par 16.

$131 S$ v Eadie (SCA) supra par 14. 
conscious control over one's action (automatism test) while simultaneously lacking self-control (the incapacity test)."

The testimony of $\mathrm{Dr}$ Jedaar on the other hand was dismissed owing to the perceived number of inconsistencies and unsatisfactory explanations in attempting to justify the appellant's conduct as well as the conflicting views given in testimony in the case of Moses. ${ }^{133} \mathrm{Dr}$ Jedaar on behalf of the State in Moses testified that one can never lose control except in a state of sane automatism. The court in Moses emphatically dismissed this testimony and stated that it flies in the face of South African law.

However, in his testimony in Eadie, Dr Jedaar in support of the appellant attempted to persuade the court that the appellant acted involuntarily due to the lack of a directing mind caused by impaired cognition and that the conduct of the appellant indicated an altered state of consciousness. However, Dr Jedaar still maintained that the appellant did not act in a state of sane automatism. ${ }^{135}$ The testimony of Dr Jedaar showed a clear lack of understanding of the basic principles of the defence and the witness was not able to differentiate between the defence of sane automatism and nonpathological incapacity despite maintaining that the appellant did not act while in a state of sane automatism.

The court was critical and unimpressed with this testimony; Navsa JA attributed the changing tunes of Dr Jedaar to the criticism levelled by the court in Moses. ${ }^{136}$ The court stated its preference clearly as being the approach of the passionate sceptic Dr Kaliski, which ultimately results in denial of the defence of non-pathological incapacity owing to provocation and emotional stress.

The court acknowledged that the new approach to the defence meant a critical reinterpretation of the formulation of the defence of non-pathological incapacity formulated in the case of Laubscher: ${ }^{137}$

"It appears to me to be clear that Joubert JA was concerned to convey, in the second leg of the test set [out] in the Laubscher case that the State has to prove that the acts which are the basis for the charges against an accused were consciously directed by him. Put differently, the acts must not have been involuntary."

Navsa JA states:

"It appears logical that when it has been shown that an accused has the ability to appreciate the difference between right and wrong, in order to escape liability, he would have to successfully raise involuntariness as a defence. In

$132 S$ v Eadie (SCA) supra referring to Louw 200114 SACJ 195 210-211, where Louw states that since there is no distinction in reality between automatism and a lack of self-control, the second leg of the capacity inquiry should fall away and capacity should be determined only on the basis of the whether a person is able to appreciate the difference between right and wrong.

$133 S$ v Moses supra discussed in $S$ v Eadie (SCA) supra par 66.

$134 S \vee$ Eadie (SCA) supra par 49.

$135 S$ v Eadie (SCA) supra par 66.

136 Ibid.

137 S v Laubscher supra.

$138 S v$ Eadie (SCA) supra par 58. 
the present contest [sic] the two are flip sides of the same coin."139

The conflation of the defence of sane automatism with the defence of nonpathological incapacity is partly due to the influence of the sceptical medical expert's views. The conflation of the two defences by a medical expert is expected since from the perspective of the medical fraternity, little recognition is given to the defence of non-pathological incapacity due to the lack of a medical theoretical foundation.

However, the views of experts such as psychologists and psychiatrists should not be allowed to encroach and undermine legal principle, which may not always be compatible with the views and opinions of the medical community. ${ }^{140}$ The medical community may not give credence to legal constructs such as loss of self-control. However, a court must make a decision based on established legal principles even when faced with expert testimony that undermine such concepts.

Eadie highlights the disconnect between the medical fraternity and the legal fraternity on what constitutes loss of self-control. In addressing the problem of differing opinions between the legal and medical fraternities in relation to the validity of the defence of non-pathological incapacity, it is submitted that the scepticism of expert witnesses towards the defence of non-pathological incapacity poses an ongoing threat in the form of influencing the court.

It is the lack of clarity regarding the nature and very existence of the defence that currently plagues the defence; and this can be attributed to Eadie, which essentially brought the law into line with neuroscience by equating the defence with sane automatism.

If there is a tension or conflict regarding the significance of the notion of loss of self-control, it is submitted that the court should rely on legal principle rather than the influence of expert testimony when laying down the law. Stevens has argued that expert testimony has contributed to the courts' conflation of sane automatism and non-pathological incapacity and has led to major disintegration of the defence, most of which is extremely unfortunate. $^{141}$

This is a travesty of justice as it results in limiting the functioning of the law and is a direct result of the court's misunderstanding of the law on an elemental level.

The nature and basis of a defence must be understood by a court. In instances where the legal principles are undermined or distorted by experts, the court is under a duty to apply and utilise the evidence to the extent that it sheds light on the case at hand. Expert evidence should not be of overriding importance.

\footnotetext{
$S v$ Eadie (SCA) supra par 57.

140 Hoctor in Joubert Essays in Honour of CR Snyman 165.

141 Stevens The Role of Expert Evidence in Support of the Defence of Criminal Incapacity 83.
} 


\section{EXPERT OPINION AND THE FINDINGS OF THE LAW COMMISSION ${ }^{142}$}

Assessment of the provocation defence in England and Canada reveals that both jurisdictions take a cautious approach in admitting expert evidence in cases involving provocation. This is due to the concern that the jury or the judge in certain instances may attach too much weight to the evidence so that the expert opinion essentially usurps the role of the jury in making a decision on the central issue. ${ }^{143}$ This is an important consideration in respect of the defence in South Africa, especially in light of the fact that the law and medicine are not in agreement on a defence based on incapacity arising from non-pathological causes.

The concerns relating to over-reliance on expert testimony and the fear of experts usurping the court's authority is a valid one. It is a struggle to achieve a balance between accepting the importance of expert evidence in coming to a fair and just result while also ensuring that the views of the expert do not unduly influence the court.

In England and Wales, the Law Commission found certain convictions were wrong in cases where expert opinions adduced by the prosecution were found to be unreliable. ${ }^{144}$ There have been problems relating to expert evidence in criminal proceedings, specifically relating to admissibility. These problems prompted calls for reform.

The Law Commission reviewed the law governing expert evidence in criminal proceedings and made useful recommendations relating specifically to expert opinion evidence. It is submitted that these could be beneficial in remedying the current problems with the defence of non-pathological incapacity due to provocation and emotional stress.

The Law Commission report Expert Evidence in Criminal Proceedings in England and Wales followed the publication of the consultation paper The Admissibility of Expert Evidence in Criminal Proceedings in England and Wales. ${ }^{146}$

In England and Wales, the Law Commission proposed a list of guidelines or factors to assist a trial judge when making a determination on the reliability and admissibility of an expert's opinion evidence. The trial judge should be directed to consider the extent and quality of the data on which the expert's opinion is based. ${ }^{147}$

Furthermore, the judge must have regard to whether the expert's opinion is founded on information that lies outside the expert's field of knowledge and, also the amount of information that was at the expert's disposal when

142 Law Commission Expert Evidence in Criminal Proceedings in England and Wales No.325.

143 Ward "Usurping the Role of the Jury? Expert Evidence and Witness Credibility in English Criminal Trial" 200913 International Journal of Evidence and Proof 8383

144 Law Commission Expert Evidence in Criminal Proceedings in England and Wales par 1.3.

145 Law Commission Expert Evidence in Criminal Proceedings in England and Wales par 1.2 in reference to Law Commission Consultation Paper No.190 (2009) par 3.15 to 3.17.

146 Law Commission Consultation Paper No.190 par 3.15 to 3.17.

147 Law Commission Expert Evidence in Criminal Proceedings in England and Wales par 5.35. 
the opinion was formed. ${ }^{148}$ The trial judge should also consider whether there is a range of expert opinion on the subject in question. If there is a range, the judge must consider where the expert's opinion falls within that range and consider the reason for the expert's bias towards the opinion proffered.

Furthermore, courts must also guard against being overly influenced by expert evidence since it is ultimately a court's assessment of the accused's state of mind that is final when ruling on whether criminal capacity was absent. In making this determination, a court assesses the facts of a case along with determining whether an accused can be classified as a reliable witness and the nature of the accused's conduct at the time of the killing. ${ }^{150}$ Hoctor argues that a court "should neither be carried away nor cowed by expert evidence"; the role of expert simply forms one component of all the evidence led. ${ }^{15}$

Better cooperation has to be ensured between the law and the medical community so that decisions are in line with the principles of justice and fairness in cases where the defence of criminal incapacity is pleaded. ${ }^{152}$ The disregard of scientific knowledge is totally unjustifiable and recognition must be accorded to modern science. If the law does not accord such recognition to modern science, then it runs the risk of "degenerating into some kind of intellectual game unrelated to the realities of life". 153

That said, it is however not the place of the medical community to demand that the assessment of criminal responsibility be exclusively a psychiatric one. It is the role of the law to define minimum standards of acceptable behaviour. However, it is pivotal that scientific psychiatric knowledge be provided when the defence of criminal incapacity is raised. Courts must welcome such evidence to the extent that it assists in explaining the behaviour and mindset of the accused at the time of commission of an offence. Medical professionals must adhere to the rules and boundaries of psychiatric evidence.

The role of medical professionals in this context is thus to provide assessment as opposed to providing a concluding opinion of criminal responsibility. This point was made clear in the case of Gesualdo ${ }^{154}$ where the court stated that the defence of non-pathological mental incapacity is one of law and not of psychology.

148 Law Commission Expert Evidence in Criminal Proceedings in England and Wales par 1.9.

149 Law Commission Expert Evidence in Criminal Proceedings in England and Wales par 5.35.

$150 S v$ Harris (1965) 2 SA 340 (A) 365B-C; $S$ v Kalagoropoulos 1993 (1) SACR 12 (A) 21J-22a; S v McDonald (2000) 2 SACR 493 (N) 501h-j; S v Ingram 1995 (1) SACR 1 (A) 4g-h; see further Hoctor in Joubert Essays in Honour of CR Snyman 129 states that this principle applies equally to cases involving the defence of sane automatism and those asking whether the accused acted voluntarily.

151 Hoctor in Joubert Essays in Honour of CR Snyman 165.

152 Le Roux and Stevens 2012 SACJ 4449.

153 Le Roux and Stevens 2012 SACJ 4466 make this point in addressing the relationship between law and the fields of psychology and psychiatry when the defence of nonpathological incapacity is assessed. However, it is submitted that the issues raised are not limited to pathological incapacity but extend also to the defence of non-pathological incapacity due to provocation and emotional stress.

154 Supra. 
The Law Commission identified the danger of lay jurors too readily accepting the opinion of an expert. In respect of expert evidence presented as fact, there is a real risk that juries will abdicate their responsibility for analysing the facts and merely accept experts' opinion evidence. This may be more prevalent where evidence is complicated and difficult for a layperson to understand and analyse.

The Law Commission found that in light of the unique nature of expert opinion evidence, there are indications that the safeguards governing the trial process are inadequate. Furthermore, in the interests of justice, only properly scrutinised and valid expert evidence should go before the jury. ${ }^{156}$ The Law Commission stated that there should be greater scrutiny of expert evidence at the stage of admissibility. ${ }^{157}$

The Law Commission explained the importance of having special rules governing the admissibility and disclosure of expert evidence during criminal proceedings. ${ }^{158}$ Expert witnesses are distinct from other witnesses; they occupy a privileged position in that they are able to provide a jury with opinion evidence on issues that are within their expertise and which may be outside a juror's realm of understanding and experience. ${ }^{159}$

\section{RELIABILITY OF EXPERT EVIDENCE: RECOMMENDATIONS OF THE LAW COMMISSION}

According to the Law Commission report, trial judges should be given a single list of standard factors to assist them in applying the reliability test. ${ }^{160}$ It recommended that a trial judge be directed to consider factors that have a bearing on expert opinion evidence under deliberation along with other relevant factors. ${ }^{16}$

The Law Commission recommended that a list of guidelines should be provided to the trial judge when determining whether the expert's opinion is sufficiently reliable to be admitted. It is submitted that such guidelines would provide practical solutions to the problems caused by a lack of regulation of expert opinion evidence in South African law.

The guidelines should assist and direct the judge to consider the following factors:

a) the basis of the expert's opinion;

b) the amount of information that was available to the expert at the time of formulating the opinion; and

155 Law Commission Expert Evidence in Criminal Proceedings in England and Wales par 1.9.
156 Law Commission Expert Evidence in Criminal Proceedings in England and Wales par 1.24.
157 Law Commission Expert Evidence in Criminal Proceedings in England and Wales par 1.27.
158 Law Commission Expert Evidence in Criminal Proceedings in England and Wales par 1.13.
159 Law Commission Expert Evidence in Criminal Proceedings in England and Wales par 1.14.
160 Law Commission Expert Evidence in Criminal Proceedings in England and Wales par 3.62.
161 Law Commission Expert Evidence in Criminal Proceedings in England and Wales par 3.63. 
c) whether there is a differing range of expert opinion in the particular field or subject, and if so, the reasons for the expert's inclination towards the stance adopted. ${ }^{162}$

Furthermore, the guidelines should provide guidance on how to assess disputed expert opinion. In relation to the reliability test, the Law Commission recommended that a rule should be enforced that if doubt exists regarding the factual integrity of expert evidence purporting to be fact, then this evidence should be regarded as expert opinion evidence. ${ }^{163}$ When assessing reliability of the expert evidence, prescribed guidelines should provide a course of action that should be taken if the factual integrity of the evidence is not certain - that is, when to classify evidence as either fact or opinion. ${ }^{164}$

In terms of the rule of "assistance", the famous English case of Turner ${ }^{165}$ had the effect over a period of 20 years of excluding expert psychological and psychiatric testimony in numerous cases where the accused was not suffering from a pathological mental disorder at the time of the commission of the act in question. The fundamental rule of "assistance" would be a valuable tool in determining whether expert opinion evidence should be admitted; the rule states that such evidence is admissible if it is able to provide the court with knowledge that is likely to be outside the understanding and experience of the judge. ${ }^{166}$

The so-called "Turner test" has been used to exclude expert evidence in cases involving duress and provocation amongst others. ${ }^{167}$ The "Turner test", which is the first leg of the common-law admissibility test works to ensure that only expert evidence that has enough probative value is admitted. The other requirements are intended to ensure that expert evidence is admitted only where the minimum threshold of general reliability is met ("reliability in the round"). ${ }^{168}$

In Canadian law, expert evidence is generally inadmissible in respect of the standard for loss of self-control and the ordinary person. ${ }^{169}$ This restrictive approach is based on two rules; the first is the "ultimate issue" rule that works to prevent an expert from expressing his view on an issue that the

162 Law Commission Expert Evidence in Criminal Proceedings in England and Wales par 1.3.

163 Law Commission Expert Evidence in Criminal Proceedings in England and Wales par 3.39.

164 Law Commission Expert Evidence in Criminal Proceedings in England and Wales par 3.62.

$165 R v$ Turner [1975] Q.B 834, C.A. In this case, the appellant was convicted of murder and sentenced to life imprisonment by the trial judge after killing his girlfriend with a hammer. One of the defences raised by the appellant was provocation. The defence based its appeal on the fact that the trial judge ruled psychiatric evidence inadmissible. The psychiatric evidence in question details the strong emotional bond the appellant shared with the deceased and this could have led to an explosive outburst even though he did not possess a mental disorder. This according to the defence was consistent with the defence of provocation. However the appeal was nevertheless dismissed.

166 Law Commission Expert Evidence in Criminal Proceedings in England and Wales par 4.8.

167 See Coleman and Mackay Legal Issues Surrounding the Admissibility of Expert Psychological and Psychiatric Testimony (1993) 47 criticising the rule in $R v$ Turner supra.

168 Law Commission Expert Evidence in Criminal Proceedings in England and Wales par 2.17.

169 Quigley 1989 University of New Brunswick LJ 29. 
jury must ultimately decide. The second rule is the "common knowledge rule" as laid down in the influential English case of Turner. ${ }^{170}$

There are dangers associated with the defence since testimony rests on the ipse dixit of the accused. One of the obvious dangers of this defence is that it is based largely on the cogency of the accused's version.

In South Africa, the court in the case of Potgieter ${ }^{171}$ was not entirely convinced of the truthfulness of the accused's version. The court ruled that the version of the accused could not reasonably be true and was thus rejected by the court. The factual foundation was held to be absent. The significant aspect in this case was that the court rejected the expert psychiatric evidence since the cogency of this evidence was based on an account that was ruled to be false. This case highlights the problems of attaching too much weight to expert evidence, which ultimately rests on the truthfulness of the accused's version. ${ }^{172}$

The following submissions are based on the four common-law principles relating to admissibility of expert evidence in English law; these are "assistance", "relevant expertise", "impartiality" and "evidentiary reliability". ${ }^{173}$

It is therefore submitted that expert opinion should be considered not sufficiently reliable if:

a) the basis of the opinion has not been subjected to adequate scrutiny or testing;

b) the opinion is based on unsound data or on indefensible assumption;

c) the opinion is dependent on an illogical conclusion;

d) on a balance of probabilities, the court concludes that the person proffering expert opinion is not qualified to give such an opinion; and

e) there is a risk that the expert may not provide objective and unbiased expert opinion evidence.

In this respect, Burchell proposes that the expert evidence should be led after evidence relating to the accused's version of events has been heard. Expert witnesses would thus have an opportunity to re-evaluate their evidence after hearing the facts of the case as well as hearing the accused's version being tested at cross-examination. This is important since psychiatric evidence is largely based on the cogency of the accused's version of events. ${ }^{174}$ It is submitted that Burchell's solutions are indeed practical and will address the problems relating to expert evidence.

\section{CONCLUSION}

Despite the controversial nature of the defence of non-pathological incapacity due to provocation and emotional stress, it continues to occupy a place in the law. The psychological or principle-based approach to

\footnotetext{
R v Turner supra; Robertson 1998 Otago LR 296.

$S v$ Potgieter 1994 (1) SACR 61 (A).

72 Burchell 1995 SACJ 38.

173 Law Commission Expert Evidence in Criminal Proceedings in England and Wales par 2.2.

174 Burchell 1995 SACJ 42.
} 
provocation and emotional stress in South African criminal law was a positive development; it preserves the integrity of the law by applying an approach that is in line with the rights and values of the Constitution of South Africa. Criminal law in South Africa has recognised the negative impact of provocation and emotional stress on self-control, which may lead to a lack of criminal capacity.

The recognition that criminal capacity can be lost through nonpathological causes such as provocation and emotional stress is a necessary validation. On this basis, the defence serves an important need in society and has earned its place in South African criminal law. ${ }^{175}$ The defence as it existed before the Eadie ${ }^{176}$ judgment did justice to South African society and was in line with fundamental principles of South African criminal law.

Unfortunately, the well-established principled nature of the defence has been drastically curtailed by the notorious case of Eadie. ${ }^{177}$ The problematic reasoning in Eadie has eroded the founding principles of the defence. ${ }^{178}$ The conflation of the defence of sane automatism with conative capacity is therefore the most troubling aspect of this case. The effects of this approach are not limited to this defence but have the potential to cause a ripple effect in other areas of law as well. ${ }^{179}$

The Eadie case effected fundamental changes - to the extent that the defence of non-pathological incapacity may have been abolished. The impact of Eadie on the existing provocation defence is grave since an accused would only be able to rely on the defence if involuntary conduct was shown.

The attempt at reformation of the defence has backfired and, in the aftermath, it is a mere shadow of the defence that it once was. The effect of the conflation is that for all practical purposes the defence of nonpathological incapacity due to provocation and emotional stress has been abolished.

Certain commentators ${ }^{181}$ felt that the defence of non-pathological incapacity due to provocation and emotional stress was intrinsically problematic since it allowed for an accused to receive an acquittal easily as demonstrated by Arnold, ${ }^{182}$ Moses $^{183}$ and Nursing ${ }^{184}$. However, the defence is a necessary part of the criminal law as it recognises a state of lack of capacity brought about by non-pathological factors.

\footnotetext{
175 Navsa JA in $S \vee$ Eadie (SCA) supra par 59 stated that such a state is notionally possible. The court recognises the defence and, if it is accepted, such a state of non-pathological incapacity is possible due to provocation or emotional stress.

$176 S$ v Eadie (SCA) supra.

$177 S v$ Eadie (SCA) supra.

178 Snyman 2003 Acta Juridica 15.

179 Snyman 2003 Acta Juridica 22.

180 Snyman Criminal Law 21-22.

181 Snyman 1985 SACJ 250-251; Burchell 1995 SACJ 41.

182 Supra.

183 Supra.

184 Supra.
} 
The problems associated with the defence prior to the Eadie ${ }^{185}$ decision cannot be ignored and must be addressed with a view to preserving the defence while effecting changes pertaining to evidentiary matters - namely, the regulation of expert testimony and defining the roles of experts. There is debate and uncertainty surrounding aspects of the defence.

The defence itself has a tumultuous history characterised by controversial acquittals. ${ }^{186}$ However, upon analysis of the history of the defence, the case law reveals that there is a definite lacuna within the defence that has prevented the defence from functioning the way it is supposed to. This deficiency relates to expert evidence, which is ironic as this defence deals precisely with incapacity brought about by non-pathological factors.

Expert evidence can be a useful aid to the court and to the accused in that an expert may provide a unique insight into the mindset of the accused. Expert testimony may also be helpful when assessing the cogency of an accused's version of events.

Accused persons who might rely on this defence, such as the battered woman, will benefit from expert evidence. Battered woman and other victims of abuse who kill their abusers stand a greater chance of succeeding in their defence by pleading non-pathological incapacity due to provocation and emotional stress. It is submitted that the defence serves an important need in society. However, the problem lies in a lack of clarity on the role of expert evidence related to this defence. The rules governing expert opinion evidence in respect of the defence of non-pathological incapacity are in need of review and legislative intervention.

Expert evidence has the power to influence and persuade. There is a real danger that unreliable expert evidence can be extremely harmful where it distorts a judge's understanding of the facts, resulting in wrong conclusions.

Expert evidence is a tool that must be used to bring about a just outcome. The trial process must provide adequate safeguards to prevent unreliable evidence from being admitted as the trial processes such as crossexamination may be unable to test the weaknesses of the evidence. The aim of the reform should be to prevent unjust acquittals by ensuring that an accused is not allowed to adduce unreliable expert opinion evidence with the intention of escaping prosecution. Reform and development is needed to formulate a new approach not only to provide clarity but also to ensure improved functioning of the defence.

Reform of the rules relating to expert evidence is necessary to ensure a fairer criminal justice system and to ensure the rights in the Constitution are promoted and protected. The Constitution and the Bill of Rights require that punishment and convictions be lawfully imposed. The criminal justice system must work to ensure that besides having well-reasoned and sound legal principles, the trial process (including the scrutiny of expert evidence) must promote the rights enshrined in the Bill of Rights. These rights include the right to freedom and security of the person in terms of section 12(1) of the

\footnotetext{
${ }^{85} S v$ Eadie (SCA) supra.

186 Hoctor in Joubert Essays in Honour of CR Snyman 131.
} 
Constitution, the right to human dignity in terms of section 10 and the right to a fair trial in terms of section 35(3)(i).

It is submitted that the prosecution should be obliged to present its own expert evidence where expert evidence has been presented in defence of an accused. This will ensure that the court obtains a balanced and wellinformed view that will work to prevent facile acquittals and ensure consistent outcomes of cases. The Law Commission's report and recommendations into expert evidence in criminal proceedings would be a useful guide in the reform of this area of law. It is recommended that the problem of experts usurping a court's role may be helped if the trial judge is directed to consider the entire body of factors. Expert opinion evidence must be considered as being just a part of the evidence and not the only determining factor.

Implementation of the aforementioned proposals and recommendations will ensure that established principles that were eroded by Eadie are restored, while also addressing a clear void in the defence of nonpathological incapacity due to provocation and emotional stress. 